\title{
13. GRAPE DENSITY RECORDS AND DENSITY CYCLICITY ${ }^{1}$
}

\author{
E. Jansen, ${ }^{2}$ L. Mayer, ${ }^{3}$ and Shipboard Scientific Party ${ }^{4}$
}

The gamma-ray attenuation porosity evaluator (GRAPE) component of the multisensor track (MST) unit on board the JOIDES Resolution measures the saturated bulk density of sediments by relating the attenuation of gamma rays in a core sample to that of a standard with known density (aluminum). After reaching thermal equilibrium, unsplit core sections are routinely run through the MST system. The sampling density chosen for the MST during Ocean Drilling Program (ODP) Leg 130 (about 2-3 cm) provides a near-continuous measurement of sediment density by means of the GRAPE equal to a resolution of $0.5-$ $3 \mathrm{k} . \mathrm{y}$., depending on the sedimentation rate.

Comparisons of GRAPE density values with discrete laboratory density measurements and downhole density logs show that absolute GRAPE density estimates are higher than both laboratory and logging density measurements; however, the downhole trends in the density data are very coherent. The constant offset between the GRAPE data and density measurements made by other means indicates that the offset is a function of the calibration of the GRAPE system. The extremely high sample resolution of the GRAPE makes it possible to use these data for a number of purposes:

1. To perform hole-to-hole correlations at a specific site, evaluating the continuity of the recovered section over core breaks. This provides a rapid method for splicing sections from one hole into missing sections in another hole or, alternatively, to evaluate possible double coring of a particular interval. GRAPE correlations can be made to depths as great as $300 \mathrm{~m}$ below seafloor (mbsf), well beyond the depth of useful magnetic susceptibility measurements.

2. To perform fine-scale, site-to-site correlations, especially in intervals with high signal-to-noise ratios or identifiable variability patterns.

3. To provide high-resolution records of environmental variations. Density variations in pelagic sediments are driven by changes in dissolution, winnowing, and dilution of carbonate by terrestrial material and opal; they therefore reflect paleoceanographic and paleoclimatic conditions.

The raw GRAPE data for Sites 803-807 were checked for quality, using the GRAPEFIX routine on the shipboard VAX computer system. Because of the slow passage of the section through the MST system required by magnetic susceptibility measurements, a number of GRAPE density measurements were often performed at a particular level. Multiple measurements were averaged using the program DECIMATE. This program was later transferred to and is now operative on the VAX system.

\footnotetext{
${ }^{1}$ Kroenke, L. W., Berger, W. H., Janecek, T. R., et al., 1991. Proc. ODP, Init. Repts., 130: College Station, TX (Ocean Drilling Program).

2 Section B, Department of Geology, University of Bergen, Allegaten 41, N5007 Bergen, Norway.

3 Department of Oceanography, Dalhousie University, Halifax, Nova Scotia, Canada B3H $4 \mathrm{~J} 1$.

${ }^{4}$ Shipboard Scientific Party is as given in the list of participants preceding the contents.
}

The raw GRAPE data commonly display very low densities in the upper portions of a core. In most cases, these low-density intervals correspond to intervals that contain disturbed and soupy sediments or flow-in.

As a first pass, an additional set of GRAPE data files were produced in which data points that came from intervals described as disturbed by the visual core description were eliminated. This was done for the section cored with the advanced hydraulic piston corer (APC) of at least one hole at each site, and it effectively eliminates most of the apparent variance related to coring disturbance. To increase the signal-to-noise ratio further, these data were smoothed by a 10-point Gaussian filter; the smoothed data sets are displayed in Figures 1 and 2. As is seen in Figure 1, there is no clear evidence of cyclicity at the core length interval $(9.5 \mathrm{~m})$, indicating that most of the disturbance signal that results from core breaks has been removed. In some cases, however, the upper parts of some cores still retain anomalously low densities, probably a result of subtle coring disturbances that are not obvious to visual examination.

Despite clear hole-to-hole and site-to-site differences in the GRAPE records, the high-frequency variations in the GRAPE records indicate that there is strong potential for detailed holeto-hole as well as site-to-site correlations. Preliminary shipboard studies based on the visual correlation of GRAPE records indicate that, in particular, the upper $\sim 100 \mathrm{~m}$ of the section are the most promising for correlation as they display the highest amplitudes and have intervals with distinct variability patterns. In Figure 2, we have plotted records from Holes $806 \mathrm{~B}$ and $807 \mathrm{~A}$, which roughly cover the interval from 1 to $2 \mathrm{Ma}$, based on shipboard biostratigraphy. It is evident from this example that the density variations at the two sites show essentially the same pattern over this interval, with a very regular cyclic appearance.

Using the preliminary shipboard age information, time-series analyses with the SPECMAP program package (Imbrie et al., 1984) were conducted on data from Holes 803B and 806B. These studies document that the GRAPE variance is closely concentrated in narrow frequency bands corresponding to the 100 , 41 , and 23 ka Milankovitch periodicities, and that the GRAPE signal is coherent with global oxygen isotope records (Imbrie et al., 1984) over the last $1 \mathrm{Ma}$ at each of these frequency bands. An example of these preliminary time-series analyses is shown in Figure 3. The analysis further documents a trend of evolving 100 -ka variation at the expense of 41 -ka spectral power through the Pleistocene, in the same manner that has previously been documented for oxygen isotope records (Ruddiman et al., 1986). This indicates that the environmental mechanisms that govern sediment density variations are linked with the ice ages and the global climate system and are strongly influenced by orbital forcing.

Shipboard studies were limited to testing the utility of the GRAPE data, and these results need more testing and development during shore-based studies. Of prime importance is the need to arrive at a clear understanding of the specific factors that control the short-term density variations in Ontong Java Plateau sediments. In addition, the more refined and accurate time scales evolving from postcruise studies must be imple- 

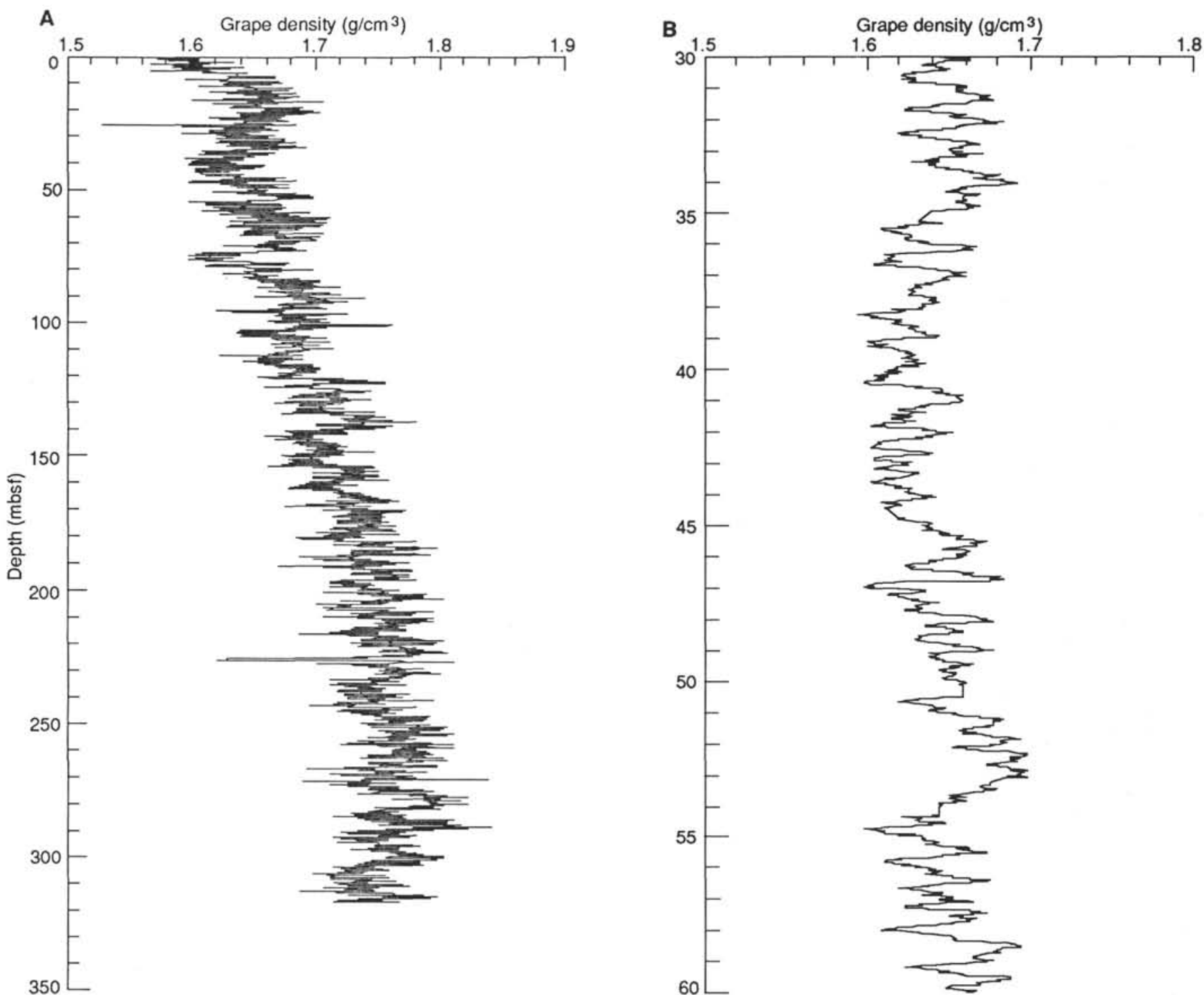

Figure 1. GRAPE density data from Hole $806 \mathrm{~B}$ plotted vs. sub-bottom depth. A. The upper $350 \mathrm{mbsf}$. B. Blown-up section with detail of the interval from 30 to 60 mbsf. The data are smoothed by a 10-pt Gaussian filter.

mented. Shipboard work, however, has already established the large potential for extremely high-resolution records of environmental change that can be extracted from the GRAPE.

\section{REFERENCES}

Imbrie, J., Hays, J. D., Martinson, D. G., McIntyre, A., and Mix, A. C., 1984. The orbital theory of Pleistocene climate: support from a revised chronology of the marine $\delta^{18} \mathrm{O}$ record. In Berger, A., Im- brie, J., Hays, J., Kukla, G., and Salzman, B. (Eds.), Milankovitch and Climate: Understanding the Response to Astronomical Forcing (Vol. 1): Dordrecht-Boston-Lancaster (D. Reidel Publ. Co.), 269-305. Ruddiman, W. R., Raymo, M., and McIntyre, A., 1986. Matuyama 41,000-year cycles: North Atlantic Ocean and Northern Hemisphere ice sheets. Earth. Planet. Sci. Lett., 80:117-129.

\section{Ms 130A-113}




\section{A}

Grape density $(\mathrm{g} / \mathrm{cm} 3)$

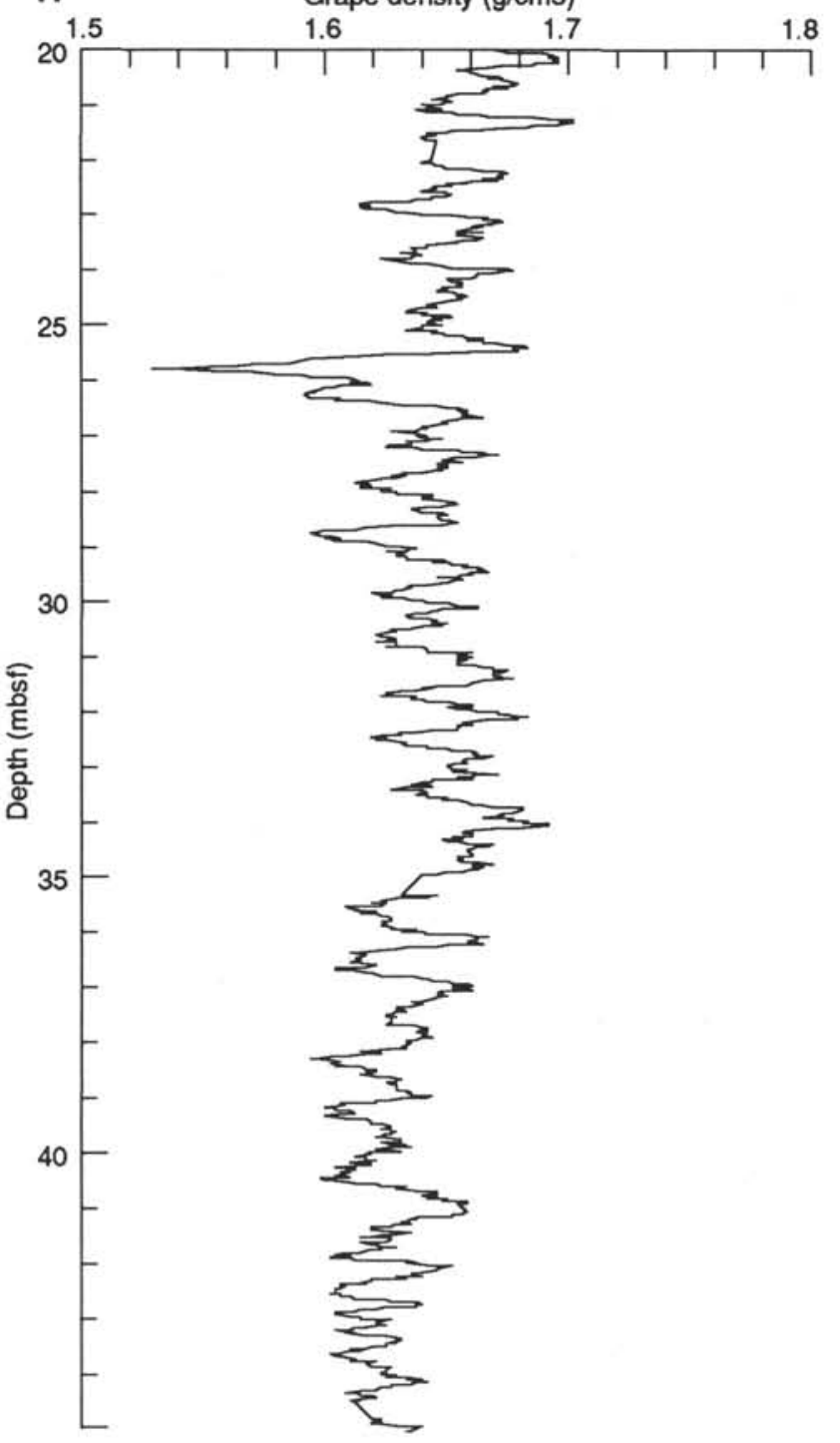

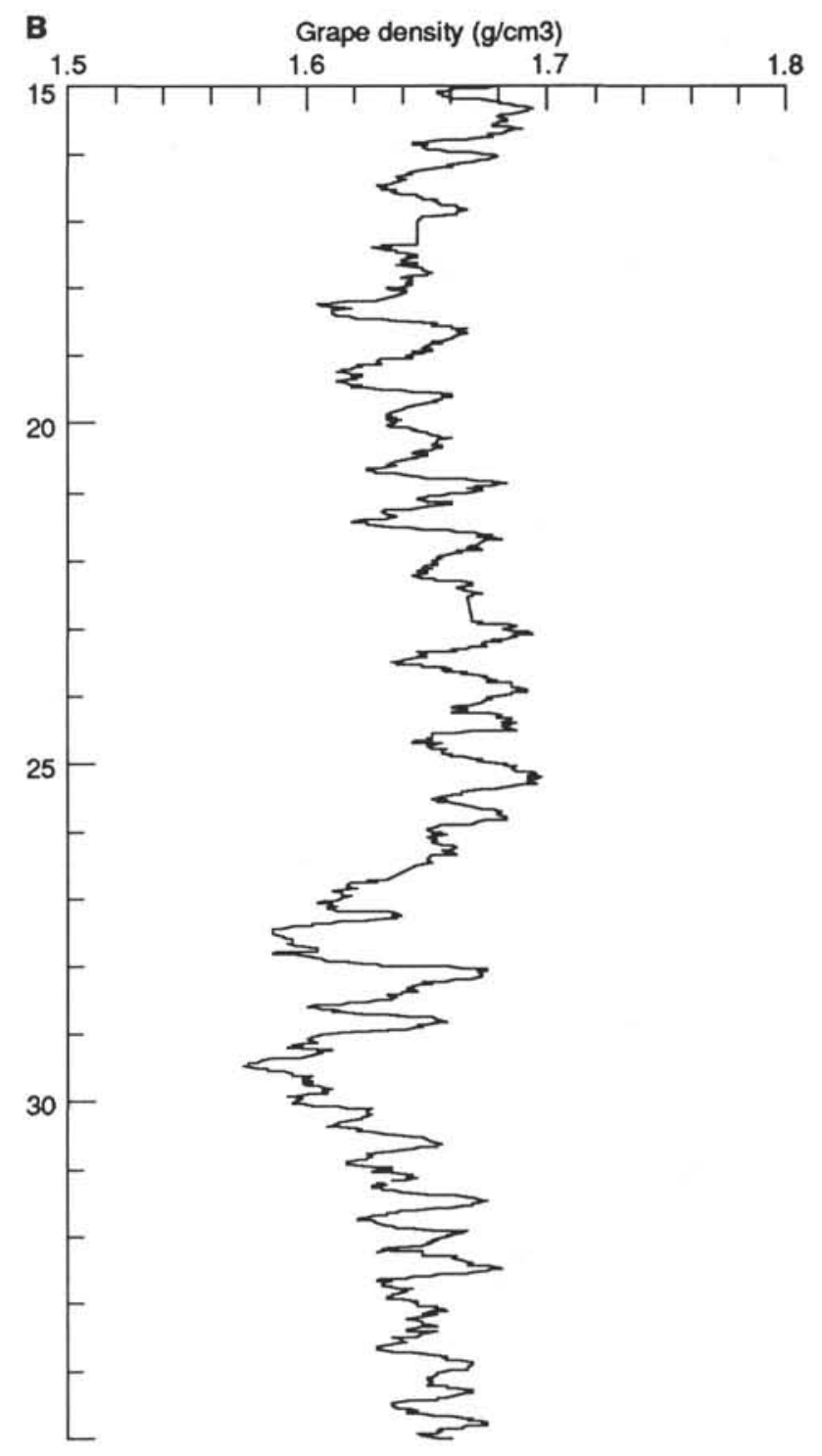

Figure 2. Smoothed GRAPE density data from Holes 806B (A) and 807A (B) plotted vs. sub-bottom depth. The selected depth intervals roughly cover the period from 1 to $2 \mathrm{Ma}$ in both holes. 


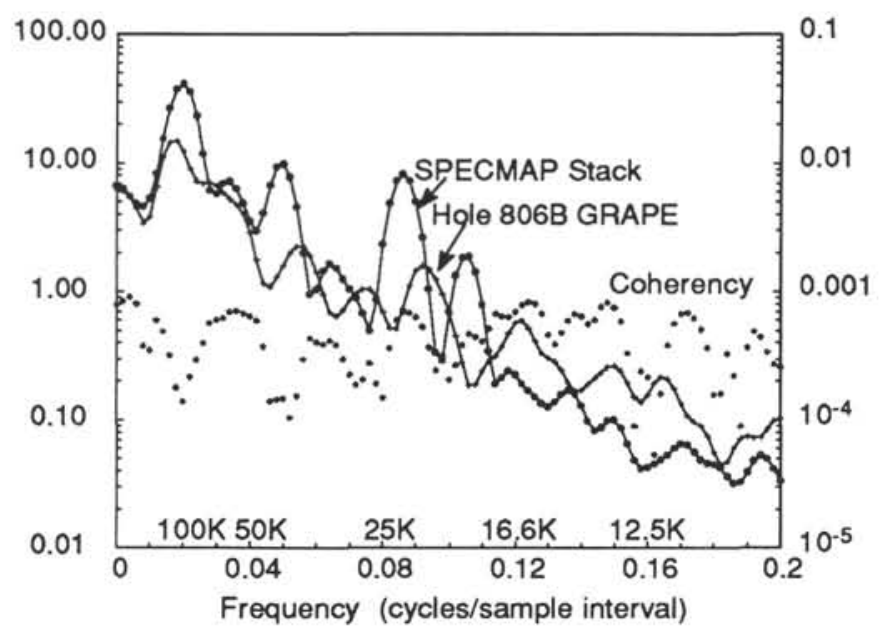

Figure 3. Example of a cross-spectral analysis of the smoothed GRAPE record from the upper $25 \mathrm{mbsf}$ in Hole $806 \mathrm{~B}$ vs. the global stack of tropical planktonic $\delta^{18} \mathrm{O}$ (SPECMAP stack; Imbrie et al., 1984). The GRAPE data used in the analysis were sampled at a constant sampling interval of $2000 \mathrm{yr}$. The results are preliminary and are based on the shipboard age model for this hole. 